\title{
Phenotypic effects of calving ease on the subsequent fertility and milk production of dam and calf in UK Holstein-Friesian heifers
}

\author{
S. A. E. Eaglen, ${ }^{*} \dagger^{1}$ M. P. Coffey, ${ }^{*}$ J. A. Woolliams, $\dagger$ R. Mrode,${ }^{*}$ and E. Wall ${ }^{*}$ \\ *Sustainable Livestock Systems Group, Scottish Agricultural College, Bush Estate, Penicuik, Midlothian, EH26 0PH, United Kingdom \\ †Roslin Institute and Royal (Dick) School of Veterinary Studies, University of Edinburgh, Roslin, Midlothian EH25 9PS, United Kingdom
}

\begin{abstract}
The effect of calving ease on the fertility and production performance of both dam and calf was studied in approximately 50,000 and 10,000 UK Holstein-Friesian heifers and heifer calves, respectively. The first objective of this study was to estimate the effect of a difficult calving on the subsequent first-lactation milk production by estimating lactation curves using cubic splines. This methodology allows the estimation of daily milk, protein, and fat yields following calvings of differing degrees of difficulty. Losses in milk yield after a difficult calving have been quantified previously; however, estimates are generally restricted to the accumulated yields at specific days in lactation. By fitting cubic splines, gaps (in which the shape of the lactation curve can be merely guessed) between estimations were avoided. The second objective of this study was to estimate the effect of a difficult birth on the subsequent performance of the calf as an adult animal. Even though the calving process is known to involve cooperation between dam and calf, the effect of a difficult calving has, until now, only been estimated for the subsequent performance of the dam. Addressing the effects of a difficult birth on the adult calf strengthens the importance of calving ease as a selection trait because it suggests that the benefit of genetic improvement may currently be underestimated. The effect of calving ease on the subsequent reproductive performance of dam and calf was analyzed using linear regression and with calving ease score fitted as a fixed effect. Dams with veterinary-assisted calvings required 0.7 more services to conception and 8 more days to first service and experienced a 28-d longer calving interval in first lactation compared with dams that were not assisted at calving. Effects of calving ease on the reproductive performance of the adult calf in first lactation were not detected. Losses in milk yield of the dam were significant between d 9 to 90 in milk subsequent to a veterinary-assisted calving, creating a loss
\end{abstract}

Received November 26, 2010.

Accepted July 24, 2011.

${ }^{1}$ Corresponding author: sophie.eaglen@sac.ac.uk of approximately $2 \mathrm{~kg}$ of milk per day, compared with a nonassisted calving. Calves being born with difficulties showed a significant reduction in milk yield in first lactation, demonstrating the lifelong effect of a difficult birth. Compared with nonassisted calves, veterinaryassisted calves showed a loss of $710 \mathrm{~kg}$ in accumulated 305-d milk yield, which was significant from 129 to 261 $\mathrm{d}$ in milk. This suggests that from birth to production, physiological effects of a bad calving are not negated. Results furthermore suggest a beneficial effect of farmer assistance at calving on the milk yield of both dam and calf, when moderate difficulties occurred.

Key words: calving ease, fertility, milk production, development

\section{INTRODUCTION}

The calving event is a key event for the dairy cow, leading to high veterinary and labor costs for the dairy cattle industry when complications occur. Adding to the importance of an easy calving is the adverse level of pain experienced by the dam (or calf) during a difficult calving, which compromises animal welfare. Therefore, not surprisingly, calving ease is reported to be an economically significant nonproduction trait (Dematawewa and Berger, 1995), which is particularly important in first-calving heifers because of their higher incidence of difficulty (Berry et al., 2007).

Parturition in cattle is a complex process that is triggered by the fetus and managed by a cascade of hormonal actions and physiological changes (Senger, 2003). Therefore, it seems logical that when complications occur, this has potential effect on normal bodily functions. Numerous studies have detected the impairment of performance after a difficult calving, with fertility traits suggested to be most affected (e.g., Laster and Gregory, 1973; Tenhagen et al., 2007). Between studies, fertility traits and definition of calving ease scores differ. However, in several measures of fertility - days open, calving interval, number of services to conception, and days to first service - an increase of units following a difficult calving is consistently concluded. Alongside fertility traits, production traits are associated with calving ease. Reported 305-d losses in cumulative milk 
yield after a difficult calving range from $300 \mathrm{~kg}$ (Djemali et al., 1987) to 500 to $700 \mathrm{~kg}$ (Dematawewa and Berger, 1997) and occur mainly during the first half of lactation (Barkema et al., 1992; Berry et al., 2007; Tenhagen et al., 2007).

The effect of calving ease on milk production is typically judged either by the analysis of accumulated milk yield at several points in lactation or by the fitting of a function such as the Wilmink exponential equation (Wilmink, 1987; Berry et al., 2007). However, currently, statistical models are capable of fitting flexible curves to longitudinal data using cubic splines (White et al., 1998), which might allow a greater insight into the precise timing and extent of losses in milk production.

Effects of complications in the perinatal period on the development and health of the offspring have been reported in humans (McNeil et al., 1970; Alonso-Spilsbury et al., 2005; Davis and Sandman, 2006; Yoder et al., 2008), sheep (Dwyer, 2008), pigs (McNeil et al., 1970), dogs (Silva et al., 2009), rats (Pan et al., 2007; Boksa and Zhang, 2008), and cattle (Hoffman et al., 1979; Lundborg et al., 2003; Lombard et al., 2007). Studies examining the effects of a difficult birth on the performance of the adult calf are, to our knowledge, rare.

Considering that both the dam and the calf undergo the same experience, albeit from different perspectives, it seems likely that complications affect not only the dam, but also the subsequent performance of the calf. This then raises the question that the assumed important aspects of calving ease, and hence the gains of genetically improving this trait, may be currently underestimated by the dairy cattle industry.

This study had 2 main objectives. First, it aimed to estimate the effects of calving ease on reproductive and production performance, using curve fitting with cubic splines for the latter. Second, this study aimed to estimate the effect of calving ease on not only the subsequent performance of the dam, but also on the calf, thereby estimating the long-term effect of a difficult birth on the performance of the calf in later life.

\section{MATERIALS AND METHODS}

\section{Data Editing}

This study was restricted to first-parity calving ease records that were collected and provided by 2 milk recording organizations (MRO) in the United Kingdom from 1995 to 2009. Calving ease data are routinely collected by one $\mathrm{MRO}$ on behalf of the breeding companies as part of their bull progeny-testing program, whereas the data from the other MRO are recorded by farmers voluntarily.
After merging the calving ease data from both sources, the data were validated for duplicates and invalid dates. Data contained only single birth calvings. The age of the dam at calving, parity, and breed of dam and sire were checked for inconsistencies and incorrect records were discarded, as were herd-year contemporary groups with fewer than 2 records.

Gestation length was derived from the last recorded insemination and calving date and restricted to 265 to $295 \mathrm{~d}$. The age of dam ranged from 18 to 40 mo. After editing, the calving ease data set consisted of 43,135 records originating from 2,824 herds.

Calving ease is generally scored on a categorical scale designed to be practical yet minimizing room for subjective interpretation. The number and definitions of categories differed between the MRO although both scales ascend in difficulty. Scoring was conducted according to a 4-grade scale by MRO A: $1=$ easy, $2=$ assisted, $3=$ difficult, and $4=$ veterinarian-assisted, whereas MRO B scored according to a 5-grade scale: $1=$ normal (not assisted), $2=$ moderate assistance (farmer), $3=$ moderate assistance (veterinarian called as precaution), $4=$ difficult (extraction by farm staff), and $5=$ very difficult calving (veterinary assistance).

To reach a unified scoring system for data analysis, categories 2 and 3 of the MRO B scale were merged, both referring to "moderate assistance required" and the latter having a very low frequency in the data $(0.43 \%)$. Thus, calving ease scores were ultimately categorized as 1 = easy (nonassisted), $2=$ moderate farmer assistance, $3=$ difficult farmer assistance, and $4=$ very difficult veterinary assistance (including caesareans).

The edited data set was subsequently matched to fertility data in the lactation following the recorded calving. This was extracted from MRO databases to create a matched fertility-calving ease data set for the dams.

All heifer calves were identified from the edited calving ease data set, specifying the difficulty of their birth, and subsequently matched to the extracted fertility data recorded in their first lactation as heifers. The same procedures were repeated to create a matched productioncalving ease data set for both the dams and the calves. In total, 4 sets of data were used in this study. Fertility and production data were collected at the same stage of life for both the dam and calf; namely, their first lactation. Data on the calf's first calving as a heifer were not available in sufficient numbers for analyses.

\section{Fertility}

Matching the calving ease data with the fertility data led to 2 sets of data with 32,480 and 8,184 records for the dam and calf, originating from 2,486 and 1,410 herds, respectively. 
The effect of calving ease on fertility in the subsequent lactation was studied by the analysis of 4 major fertility traits: calving interval (CI), number of inseminations (NRINS), the binary trait of nonreturn at 56 d (NR56; 0 = failure, 1 = success), days to first service (DFS), and BCS as an associated trait. Calving interval was restricted to between 300 and $600 \mathrm{~d}$ and DFS to between 20 and $200 \mathrm{~d}$. The age of the dam ranged from 19 to 40 mo (first-parity heifers, average age of dam equaled $24.3 \mathrm{mo}$ ), in line with national genetic evaluations. Body condition was scored in the field by breed society classifiers in the first half of the lactation (between 80 and 140 DIM) on a scale from 1 to 9 , where $1=$ thin and $9=$ fat. Scores were then adjusted for classifier by scaling records so the individual standard deviations were equal to the mean standard deviation of all classifiers (Brotherstone, 1994).

\section{Production}

Merging the calving ease data with individual monthly milk test-day records from national milk recording databases led to 2 sets of data with a total of 338,665 and 80,679 milk test-day records of 39,473 heifers and 9,507 calves, respectively. The mean number of milk yield records per lactation per individual was 7 , with a maximum of 10 . The effect of calving ease on milk production in the subsequent lactation, for both dam and calf, was studied by the analysis of 6 production traits: milk yield, fat yield (FY), fat percentage, protein yield $(\mathbf{P Y})$, protein percentage, and SCC. Milk yield records $>3$ standard deviations from the mean milk yield within DIM were deleted, and age of dam ranged from 18 to 40 mo.

\section{Statistical Analysis}

For all models, preliminary least squares analyses using the PROC MIXED option of SAS (SAS Institute, 2006) were used to select significant fixed effects to be included. Subsequently random effects were added and analyses were conducted using ASREML v2.0 (Gilmour et al., 2006).

\section{Fertility}

Preliminary least squares analyses using the PROC MIXED option (SAS Institute, 2006) were used to select significant fixed effects to be included in the model. Subsequently, fertility traits were analyzed using linear regression and REML using ASREML v2.0 (Gilmour et al., 2006), with calving ease fitted as a fixed effect. Least squares means of the y-value within each calving ease category were subsequently estimated. The general linear mixed model illustrated by Equation [1] was used for analyses of both dams and calves. A generalized linear mixed model fitting a logit link function was used for the analysis of the binary trait of NR56:

$$
\mathbf{y}=\mathbf{X b}+\mathbf{Z u}+\mathbf{e}
$$

where $\mathbf{y}$ is a vector of fertility trait records [CI, NRINS (count), NR56, BCS, DFS]; $\mathbf{X}$ and $\mathbf{Z}$ are known incidence matrices; $\mathbf{b}$ is a vector of fixed correction factors consisting of sex of calf (only fitted in analyses of the dams), age in months at calving $(18,19, \ldots, 40)$, year of calving $(1994,1995, \ldots, 2009)$, month of calving (January, February, ..., December), calving ease category $[1=$ easy (nonassisted) to $4=$ veterinary assistance], and data source (MRO A or B). Depending on the trait analyzed, fixed covariates added were DIM and days pregnant. $\mathbf{u}$ is a vector of the random correction factor of herd-year with $\mathbf{u} \sim N\left(0, \mathbf{I} \sigma_{h y}^{2}\right)$; and $\mathbf{e}$ represents the vector of error terms with $e \sim N\left(0, \mathbf{I} \sigma_{e}^{2}\right)$.

\section{Production}

To account for and estimate the general shape of the lactation curve for groups of cows in the same calving ease category, production traits were analyzed using repeated-measurement analysis. A linear mixed model was fitted, integrating a cubic smoothing spline to the test-day records within each calving ease category. This led to estimation of 4 smoothing parameters and sets of curve values, creating 4 smoothing splines, each representing a lactation curve following a specific calving ease category. The ASREML program fits, by default, 50 equally spaced knot points to the data.

To account for the variation of test-day measurements at different stages of lactation, residual error classes were fitted. The borders of the residual error classes were based on previous work by Coffey et al. (2002) and Wall et al. (2005) and adjusted to the current data, which led to 10 fitted error classes.

The linear mixed model fitted for the analyses of the dams and calves was

$$
\mathbf{y}=\mathbf{X b}+\mathbf{Z u}+\mathbf{Z}_{\mathbf{s}} \mathbf{u}_{\mathbf{s}}+\mathbf{e},
$$

where $\mathbf{y}$ is a vector of production trait records (milk yield, FY, PY, fat percentage, protein percentage, SCC); $\mathbf{X}$ and $\mathbf{Z}$ are known incidence matrices linking observations to fixed effects and random correction factors; $\mathbf{Z}_{\mathrm{s}}$ is an incidence matrix containing the spline coefficients for each DIM; $\mathbf{b}$ is a vector of fixed correction factors consisting of age in months at calving (dams, 18, .., 40) or year of birth (calves, 1995, ..., 2007), year of calving $(1994, \ldots, 2009)$ and data source 
(A or B). Vector $\mathbf{b}$ also incorporates the linear part of the fitted cubic splines, calving ease category, DIM (fitted as a covariate), and the interaction term of calving ease category $\times$ DIM; $\mathbf{u}$ is a vector of the random correction factor of herd-test-day (effect specific for all the cows on the same test-day within herd) and the permanent environmental effect, with values assumed to be independent and following normal distributions; $\mathbf{u}_{\mathrm{s}}$ is a vector chosen to minimize a roughness penalty, $\alpha \mathbf{u}_{\mathrm{s}} \mathbf{R} \mathbf{u}_{\mathrm{s}}$, with smoothing parameter $\alpha$ to be estimated by the model, and $\mathbf{R}$ being a symmetric matrix that is a function of the knot points (White et al., 1999); and e represents the vector of error terms, with $\mathbf{e} \sim N\left(0, \mathbf{I} \sigma_{e}^{2}\right)$.

\section{RESULTS}

The frequency of calving ease in each of the 4 data sets is reported in Table 1. A lower frequency of difficult births is shown in the calf data sets, which was the result of the merging of data sets. For the merging procedure, only the heifer calves were isolated from the calving ease data set to match with the adult calf performance data sets. Sex is a significant contributor to calving ease and female calves are known to be born more easily (Meijering, 1983). Discarding the bull calves therefore causes a difference in calving ease frequency between the dam and calf data sets. The calving ease frequencies found in these data are very consistent with the literature, with approximately 70 to $80 \%$ nonassisted calvings for primiparous cows (Djemali et al., 1987; Dematawewa and Berger, 1997; Lombard et al., 2007).

\section{Effect of Calving Ease on Subsequent Reproductive Performance}

Figure 1 shows a consistent trend in which a decrease in calving ease (categories 2, 3, 4 vs. category 1) was associated with a decrease in reproductive performance. A summary of significant results for the effect of a difficult calving on the subsequent reproductive performance of the dam is given in Table 2. Here, estimated least squares means were set to 0 for calving ease category 1 (easy, nonassisted), which then served as a base of reference for comparison with the other categories, ascending in difficulty.

Dams in need of veterinary assistance (category 4) at calving required 0.7 more services [standard error of the difference $(\mathbf{S E D})=0.10]$ to conception, had 8 more days to first service $(\mathrm{SED}=2.3)$, and experienced a 28-d longer calving interval $(\mathrm{SED}=8.1)$ compared with nonassisted dams (category 1 ). The probability to return to estrus after $56 \mathrm{~d}$ showed a tendency $(P=$ $0.06)$ to increase by $11 \%$ when veterinary assistance was required compared with a nonassisted calving.
Body condition score of the dam in the subsequent lactation (scored between 80 and 140 DIM) was significantly lower following a farmer-assisted calving (categories 2 and 3) compared with a nonassisted calving. However, a significant increase in BCS was shown between veterinary- and farmer-assisted calvings. The increase in BCS when calving ease exceeded category 3 suggests a clear difference in the amount of difficulty or assistance experienced between calvings scored within category 3 and category 4 .

This study failed to detect an effect of calving ease on the subsequent fertility of the adult calves in their first lactation. From this study, we cannot conclude that a difficult birth has a long-term effect on the reproduction performance of the adult calf in first lactation. Results on both dams and calves are represented in Figure 1. This figure excludes the trait of NR56 because a significant effect of calving ease was not found in either dams or calves.

\section{Effect of Calving Ease on Subsequent Production Performance}

Dams. The effect of calving ease on milk, fat, and protein production in the subsequent lactation of both the dam and the adult calf is shown by the estimated lactation curves in Figure 2. Each estimated curve, within a trait, represents a separate category of calving ease.

Veterinary-assisted dams showed a decrease in milk production compared with nonassisted dams, which was significant between 10 and 90 DIM, creating a loss in milk yield of approximately $2 \mathrm{~kg} / \mathrm{d}$. Figure 2 illustrates that calving ease does not alter the shape of the lactation curve to a large extent. The peak of the lactation curve after a veterinary-assisted calving was flatter and milk yield decreased more gradually compared with that after a nonassisted calving. Around d 190, milk yield then met the level produced by a nonassisted dam. Significant daily loss in milk is therefore estimated to occur solely in the beginning of lactation.

Table 1. Frequency distribution (\%) of the 4-category calving ease scale within the production and fertility data sets for cows and calves

\begin{tabular}{lrrrrrr}
\hline & \multicolumn{2}{c}{ Fertility } & & \multicolumn{2}{c}{ Production } \\
\cline { 2 - 3 } \cline { 5 - 6 } Category $^{1}$ & Cow & Calf & & Cow & Calf \\
\hline 1 & 74.02 & 79.70 & & 74.90 & 80.55 \\
2 & 22.07 & 18.68 & & 21.39 & 18.04 \\
3 & 3.19 & 1.38 & & 3.00 & 1.18 \\
4 & 0.72 & 0.23 & & 0.71 & 0.24 \\
\hline 1
\end{tabular}

${ }^{1} 1=$ easy (nonassisted); $2=$ moderate farmer assistance; $3=$ difficult farmer assistance; 4 = very difficult with veterinary assistance. 
Table 2. The effects of different degrees of calving ease on the subsequent reproduction performance of the dam expressed as deviations from calving ease score 1 (standard errors of the difference are given in parentheses)

\begin{tabular}{|c|c|c|c|c|}
\hline \multirow[b]{2}{*}{ Trait } & \multicolumn{4}{|c|}{ Calving ease category $^{1}(P<0.05)$} \\
\hline & 1 & 2 & 3 & 4 \\
\hline $\begin{array}{l}\text { Calving interval }(\mathrm{d}) \\
\text { Number of services } \\
\text { Days to first service } \\
\text { Nonreturn rate at } 56 \mathrm{~d}(\mathrm{NR} 56)^{2} \\
\text { BCS (units) }\end{array}$ & $\begin{array}{l}0.0^{\mathrm{a}} \\
0.0^{\mathrm{a}} \\
0.0^{\mathrm{a}} \\
0.0^{\mathrm{a}} \\
0.0^{\mathrm{a}}\end{array}$ & $\begin{array}{c}4.0^{\mathrm{b}}(1.37) \\
0.1^{\mathrm{b}}(0.02) \\
1.7^{\mathrm{b}}(0.51) \\
-0.04^{\mathrm{b}}(0.03) \\
-0.06^{\mathrm{b}}(0.04)\end{array}$ & $\begin{array}{c}6.9^{\mathrm{b}}(3.47) \\
0.2^{\mathrm{b}}(0.04) \\
3.5^{\mathrm{bc}}(1.10) \\
-0.02^{\mathrm{ab}}(0.04) \\
-0.18^{\mathrm{b}}(0.08)\end{array}$ & $\begin{array}{c}28.0^{\mathrm{c}}(8.05) \\
0.7^{\mathrm{c}}(0.10) \\
7.8^{\mathrm{c}}(2.29) \\
-0.11^{\mathrm{ab}}(0.06) \\
0.27^{\mathrm{a}}(0.16)\end{array}$ \\
\hline
\end{tabular}

The accumulated 305-d milk showed a nonsignificant reduction in milk of $153 \pm 102 \mathrm{~kg}$ (Table 3 ).

The methodology of curve modeling with use of curve parameters produces daily estimates for every DIM. Therefore, the accumulated 305-d yield presented in Table 3 is the sum of all estimated daily milk yields, up to $\mathrm{d} 305$, and not a result of a statistical analysis on the accumulated milk yield to d 305 .

A reduction in milk yield is logically accompanied by a reduction in fat yield and protein yield, represented by graphs FY (d) and PY (d) in Figure 2. A significant reduction in fat and protein percentages was not observed, which suggests that milk composition was not altered by the occurrence of difficulties during calving. This study failed to detect an effect of calving ease on SCC, suggesting no association of difficulty at calving with the occurrence of mastitis infections or other inflammations in the udder.

Figure 2 shows a consistent trend throughout all the graphs presented. The lactation curve following a

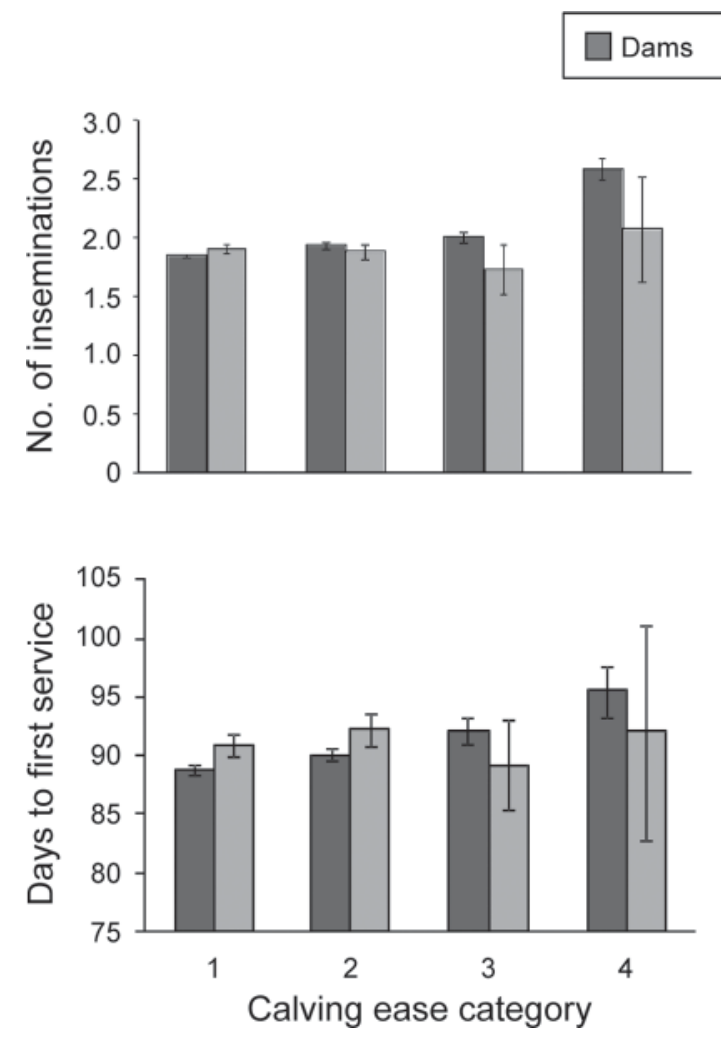

\section{Calves}
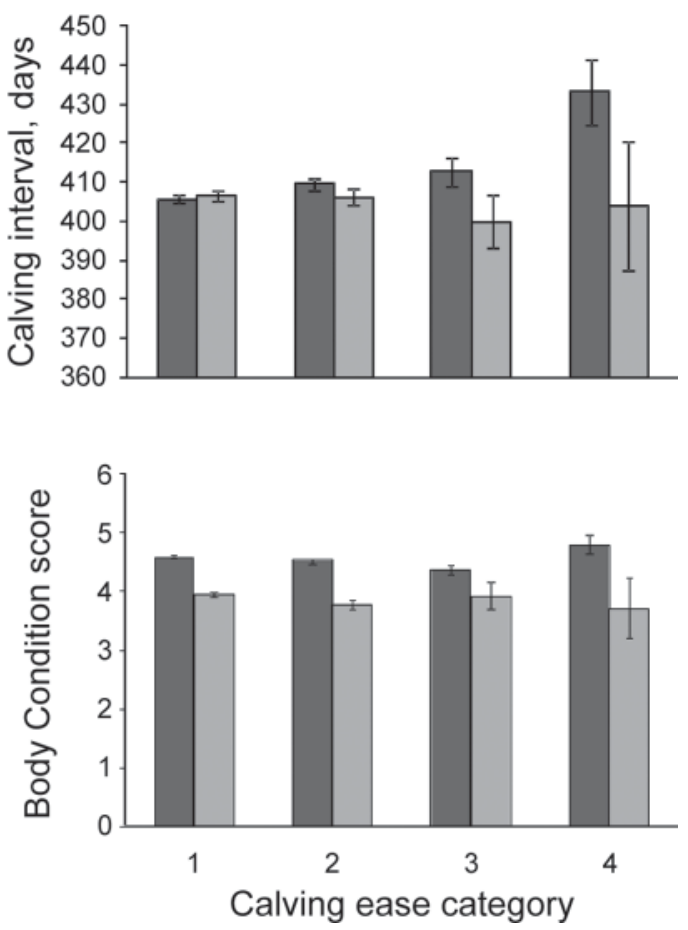

Figure 1. The effect of different degrees of calving ease on the subsequent number of inseminations (NRINS), calving interval (CI), days to first service (DFS), and BCS of the dam and the calf as an adult heifer. Error bars indicate the magnitude of standard errors. 


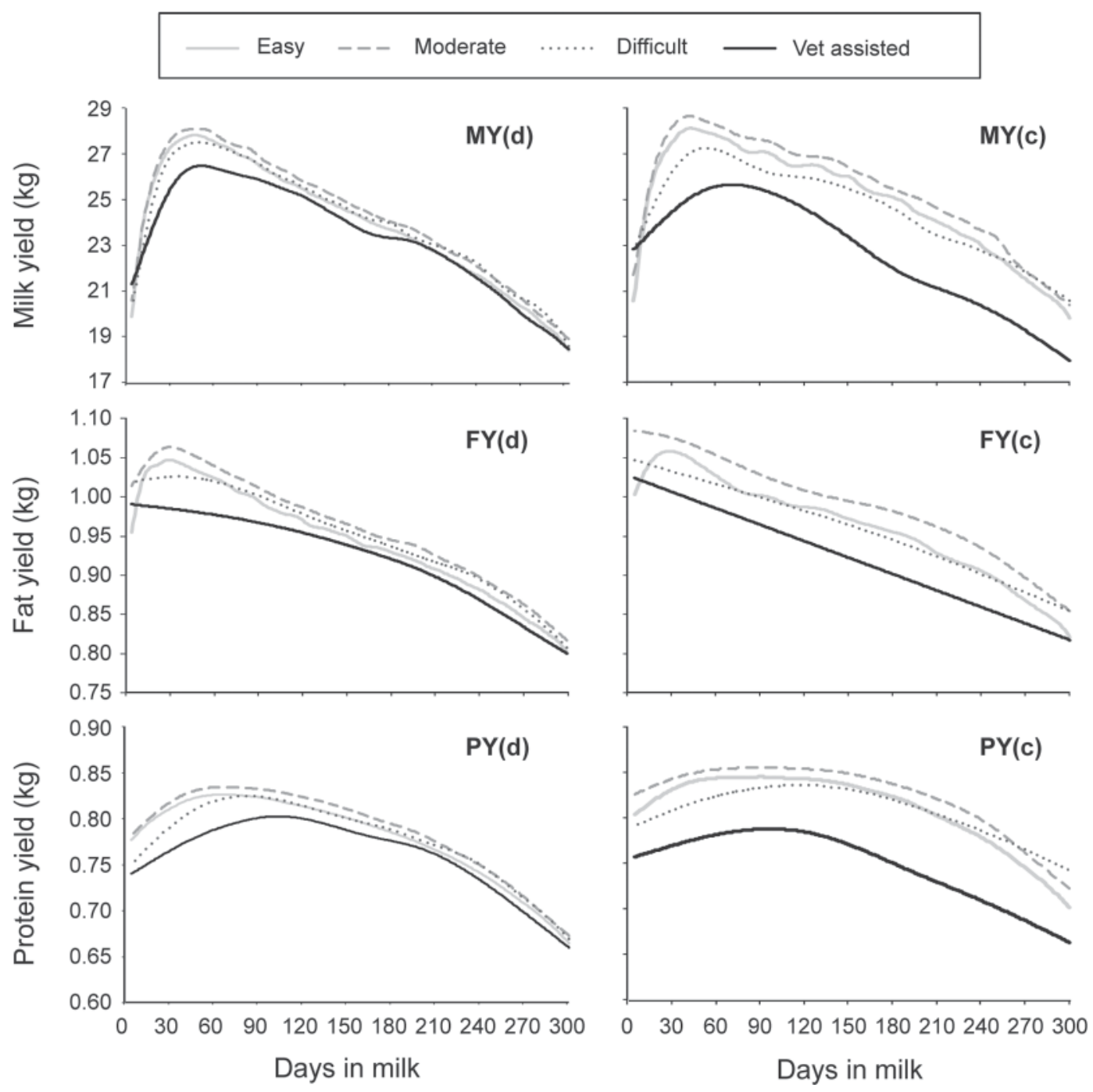

Figure 2. The effects of different degrees of calving ease on the subsequent milk, fat, and protein yields of both the dams and calves as grown-up heifers. Here, "d" refers to the graphs representing the performance of the dams, and "c" refers to the performance of the calves as grown-up heifers. $\mathrm{MY}=$ milk yield; $\mathrm{FY}=$ fat yield; $\mathrm{PY}=$ protein yield.

veterinary-assisted calving was consistently the lowest curve in the graphs, whereas the lactation curve following a moderate farmer-assisted calving (category 2) was always the top curve. The increase in daily milk production levels for a moderate farmer-assisted calving compared with a nonassisted calving remained significant until the end of lactation, from d 19 to 304. The accumulated 305-d increase in milk yield was estimated to be $108 \mathrm{~kg}$, or approximately $0.5 \mathrm{~kg}$ per DIM. The 305-d accumulated milk loss between a farmerassisted moderate calving and veterinary-assisted calving (significant from d 11 to 184 in milk) was estimated to be $262 \pm 104 \mathrm{~kg}(4 \% \pm 2 \%)$, or $1.5 \mathrm{~kg}$ per DIM, which approaches the range of 300 to $700 \mathrm{~kg}$ reported in the literature (Djemali et al., 1987; Dematawewa and Berger, 1997; Fourichon et al., 1999).
Calves. Figure 2 presents the effect of different degrees of calving ease on subsequent milk, fat, and protein production of the adult calves and shows very similar trends to the curves representing the production performance of the dams. Compared with nonassisted calves, those delivered with veterinary assistance show a loss in milk production as adult heifers. The shape of the lactation curve was not affected by calving ease in the dams. However, for adult calves, a delay in reaching peak milk yield was observed, with veterinary-assisted calves reaching peak milk yield approximately 1 mo later than nonassisted calves. The lower level of milk production following a veterinary-assisted birth compared with a nonassisted birth was estimated to be significant from 129 to 261 DIM; a strong trend $(P=$ $0.055)$ was estimated for the first part of lactation. The 
Table 3. The effects of different degrees of calving ease on the subsequent yields of milk, fat, and protein of the dam (standard errors are given in parentheses)

\begin{tabular}{|c|c|c|c|c|c|}
\hline \multirow[b]{2}{*}{ Trait } & \multirow[b]{2}{*}{ DIM } & \multicolumn{4}{|c|}{ Calving ease category $^{1}(P<0.05)$} \\
\hline & & 1 & 2 & 3 & 4 \\
\hline \multicolumn{6}{|c|}{ Milk yield (kg) } \\
\hline & 100 & $26.11(0.29)$ & $26.52(0.29)$ & $26.21(0.32)$ & $25.62(0.41)$ \\
\hline & 200 & $23.13(0.29)$ & $23.54(0.29)$ & $23.40(0.31)$ & $23.00(0.41)$ \\
\hline & 300 & $18.54(0.29)$ & $18.93(0.30)$ & $18.77(0.35)$ & $18.49(0.48)$ \\
\hline & $\mathrm{Cum}^{2}$ & $7,218.73^{\text {ac }}(104)$ & $7,326.91^{\mathrm{a}}(105)$ & $7,249.22^{\mathrm{a}}(108)$ & $7,064.85^{\mathrm{c}}(119)$ \\
\hline \multicolumn{6}{|c|}{ Fat yield (kg) } \\
\hline & 100 & $0.98(0.01)$ & $1.00(0.01)$ & $0.99(0.01)$ & $0.96(0.02)$ \\
\hline & 200 & $0.92(0.01)$ & $0.94(0.01)$ & $0.93(0.01)$ & $0.91(0.02)$ \\
\hline & 300 & $0.80(0.01)$ & $0.82(0.01)$ & $0.80(0.02)$ & $0.80(0.02)$ \\
\hline & Cum. & $283.75^{\mathrm{a}}(17)$ & $288.95^{\mathrm{a}}(17)$ & $285.43^{\mathrm{a}}(17)$ & $277.56^{\mathrm{a}}(17)$ \\
\hline Protei & 100 & $0.82(0.01)$ & $0.83(0.01)$ & $0.82(0.01)$ & $0.80(0.01)$ \\
\hline & 200 & $0.77(0.01)$ & $0.78(0.01)$ & $0.78(0.01)$ & $0.77(0.01)$ \\
\hline & 300 & $0.66(0.01)$ & $0.67(0.01)$ & $0.67(0.01)$ & $0.66(0.02)$ \\
\hline & Cum. & $234.31^{\mathrm{a}}(15)$ & $236.76^{\mathrm{a}}(16)$ & $233.72^{\mathrm{a}}(15)$ & $228.56^{\mathrm{a}}(16)$ \\
\hline
\end{tabular}

significant reduction in accumulated 305-d milk yield, presented in Table 4, was estimated to be $703 \pm 251$ $\mathrm{kg}(9 \% \pm 3 \%)$ for a veterinary-assisted calf compared with a nonassisted calf. Similar to findings in dams, higher milk yield levels are shown by calves delivered with moderate farmer assistance compared with no assistance. This benefit is expressed by an estimated increase in accumulated 305-d milk yield of $153 \mathrm{~kg}$, or $0.5 \mathrm{~kg} / \mathrm{d}$, and was significant throughout the lactation.

Note that the calf data set was small (9,507 calves) compared with the dam data set and therefore the number of animals, especially in categories 3 and 4, was low. Therefore, estimated standard errors are relatively large.

\section{DISCUSSION}

This study found substantial effects of calving ease on the subsequent reproductive performance of the dam but failed to detect any effects on the reproductive performance of the adult calf in first lactation. Lactation curves estimated by using curve fitting show significant effects of calving ease on the milk production of the dam as well as the calf. To our knowledge, this is the first study to determine detrimental effects of a difficult birth on performance of the calf later in life, using national data. No effect of calving ease on SCC was found, in accordance with Berry et al. (2007). Comparing the estimated effects of calving ease found in this study with estimates in the literature is difficult (Fourichon et al., 1999) because scoring procedures vary widely among studies by using different numbers and definitions of categories. Even though the highest category generally refers to veterinary-assisted calvings and the lowest to calving with "no difficulties," categories that lie between are not consistent in definitions. Furthermore, the rearrangement of recorded scores into assisted and nonassisted calvings, preceding statistical analysis, is not uncommon (Berry et al., 2007). As in the results, emphasis in the discussion therefore lies in differences between the outer classes of the 4-grade scale (1 vs. 4$)$, where score 4 (veterinary assistance) included caesareans.

\section{Effect of Calving Ease on Subsequent Reproductive Performance}

Although many studies have reported detrimental effects of calving ease on all the fertility traits analyzed in this study (Thompson et al., 1983; Erb et al., 1985; Djemali et al., 1987; Simerl et al., 1992; Dematawewa and Berger, 1997), a few studies did not find significant results (Laster et al., 1973; Tenhagen et al., 2007). However, in these studies, sample sizes were small and it was acknowledged that severe difficulty at calving decreases conception rate to AI and the likelihood of conceiving within 200 DIM. The estimated effects of a difficult calving on subsequent reproduction performance in the current study are of similar magnitude to estimates reported in the literature. Reported estimates range from 0.2 to 0.4 more services for NRINS, from 14 to $45 \mathrm{~d}$ longer CI or days open, from 4 to $8 \mathrm{~d}$ for 
Table 4. The effects of different degrees of calving ease on the subsequent yields of milk, fat, and protein of the calf as an adult heifer (standard errors are given in parentheses)

\begin{tabular}{|c|c|c|c|c|c|}
\hline \multirow[b]{2}{*}{ Trait } & \multirow[b]{2}{*}{ DIM } & \multicolumn{4}{|c|}{ Calving ease category ${ }^{1}(P<0.05)$} \\
\hline & & 1 & 2 & 3 & 4 \\
\hline \multicolumn{6}{|c|}{ Milk yield (kg) } \\
\hline & 100 & $26.77(0.15)$ & $27.27(0.19)$ & $26.10(0.53)$ & $25.16(1.16)$ \\
\hline & 200 & $24.35(0.15)$ & $24.95(0.19)$ & $23.88(0.53)$ & $21.22(1.16)$ \\
\hline & 300 & $19.82(0.18)$ & $20.45(0.23)$ & $20.67(0.72)$ & $17.40(1.83)$ \\
\hline & $\mathrm{Cum}^{2}$ & $7,502.74^{\mathrm{ab}}(59)$ & $7,655.81^{\mathrm{a}}(93)$ & $7,384.01^{\mathrm{b}}(134)$ & $6,798.89^{\mathrm{c}}(245)$ \\
\hline \multicolumn{6}{|c|}{ Fat yield (kg) } \\
\hline & 100 & $0.99(0.01)$ & $1.01(0.01)$ & $0.97(0.02)$ & $0.99(0.05)$ \\
\hline & 200 & $0.94(0.01)$ & $0.97(0.01)$ & $0.94(0.02)$ & $0.87(0.05)$ \\
\hline & 300 & $0.82(0.01)$ & $0.85(0.01)$ & $0.85(0.03)$ & $0.82(0.08)$ \\
\hline & Cum. & $289.03^{\mathrm{a}}(12)$ & $297.32^{\mathrm{a}}(17)$ & $287.97^{\mathrm{a}}(17)$ & $276.78^{\mathrm{a}}(19)$ \\
\hline \multicolumn{5}{|c|}{ Protein yield (kg) } & $0.80(0.04)$ \\
\hline & 200 & $0.81(0.01)$ & $0.82(0.01)$ & $0.81(0.02)$ & $0.73(0.04)$ \\
\hline & 300 & $0.70(0.01)$ & $0.72(0.01)$ & $0.74(0.02)$ & $0.63(0.06)$ \\
\hline & Cum. & $243.55^{\mathrm{a}}(14)$ & $247.87^{\mathrm{a}}(16)$ & $242.95^{\mathrm{a}}(16)$ & $224.93^{\mathrm{a}}(17)$ \\
\hline
\end{tabular}

DFS, and a decrease in probability of NR56 by 0.14 to 0.25 for a veterinary-assisted calving compared with a nonassisted calving (Meijering, 1983; Thompson et al., 1983; Mangurkar et al., 1984; Erb et al., 1985; Djemali et al., 1987; Simerl et al., 1992; Dematawewa and Berger, 1997).

Good fertility in dairy cows can be defined as the establishment of pregnancy at the desired time (Pryce et al., 2004). As conception is the result of a chain of events, failure to establish pregnancy can be the result of malfunction at any link in the chain (Garnsworthy et al., 2008). However, the consistency in reported results on DFS suggests that problems start early in this chain after a difficult calving, with a struggle to return to normal cyclicity. Anestrus following a difficult calving is a prolonged luteal phase due to the lack of luteal regression (Peter et al., 2009). A stressful event, such as a difficult calving, can act as an acute stressor affecting the hypothalamic function in such a way that results in abnormal ovarian function, which then delays or prohibits the surge of luteinizing hormone (LH) necessary for ovulation (Dobson et al., 2001). Such mechanisms are consistent with the results of Zhang et al. (1999), who report delays in the decline of progesterone concentration found in heifers after having had a difficult calving.

After calving, high energy requirements for milk production force the dam into a period of negative energy balance. To offset energy required in excess of ingested energy, body tissue is catabolized and consequently BCS decreases. Additional stress due to a difficult par- turition might cause a greater negative energy balance due to reduced appetite (Ingvartsen et al., 2003). A reduction in BCS experienced after a difficult calving, as found in this study, does not seem surprising, and is supported by other reports in dairy (Berry et al., 2007) and beef cattle (Drennan and Berry, 2006). A very high BCS is frequently associated with a higher risk of experiencing a difficult calving (Meijering, 1983; Mee, 2008). In this context, the greater than expected BCS found to be associated with a veterinary calving in this study may be an indirect consequence of high BCS at parturition. Such an inference is acceptable because BCS in this study was scored in the first part of the lactation. Higher BCS found in veterinary-assisted dams compared with nonassisted dams could also be associated with additional findings of this study showing a lower milk production following veterinary assistance. However, further studies will be required to explore fully the consequences a difficult calving on BCS postpartum.

\section{Effect of Calving Ease on Subsequent Production Performance}

Dams. This study showed that by use of curve fitting with cubic splines, lactation curves can be estimated, showing the milk, fat, and protein yields per DIM after calvings of different ease. With this method, "gaps" are avoided between estimations of accumulated milk yields at specific DIM. By comparing the estimated lactation curves, it was possible to determine accurately 
when losses in milk yield occur and around which day differences lose statistical significance. We showed that losses in milk yield after a veterinary-assisted calving compared with a nonassisted calving were significant up to 90 DIM. After 90 DIM, differences in milk yields gradually decreased and became negligible around 190 DIM. These results explain why the effect of calving ease was only reported to be significant in the first stage of lactation by studies analyzing accumulated 30, 60, 90, 120, and 240 DIM yields (Thompson et al., 1983; Tenhagen et al., 1999; Berry et al., 2007). By having fitted cubic splines, daily milk yields and milk production trends can be accurately compared between calving ease categories. This allowed us to determine that no evidence exists for compensatory milk production, something that could not have been concluded from analyses on accumulated milk yields at specific DIM. The lack of statistical significance for later accumulated yields is due to the additional variance and dilution of the effect.

The estimated lactation curves in this study show a moderate benefit in milk yield when farmer assistance was provided at a calving of moderate difficulty (category 2). Biologically, it appears illogical that a decrease in calving ease would be related to an increase in milk production. Therefore, it seems sensible to consider this phenomenon as being an artifact of industry-recorded data. In that context, the estimated benefit in milk production can be supported by various hypotheses, or most likely, a combination of these. First, the presence of a farmer at parturition might indicate preferential treatment. This could be in the form of additional care provided to the animals by nutrition, or an isolated location, that is beneficial to their milk production. The animals involved in a farmer-assisted calving may be of higher value, with associated expectations. For example, animals of comparatively high genetic merit for yield in the herd are more readily offered assistance. Second, it is inevitable that a considerable number of calvings are unobserved by the farmer. Therefore, witnessing a healthy cow and calf may encourage the farmer to assume the calving went as desired and score it as a calving of category 1 . However, the exact amount of difficulty experienced by the dam and calf remains unknown, thereby biasing the category defined as "easy." This bias, if one assumes that difficult calvings will reduce yield to some degree, would then lead to a depression of yield in the "easy" class.

In this study, the occurrence of stillbirths or retained placenta has not been corrected for. Both retained placenta and stillbirth have been associated with loss in milk yield (Rowlands and Lucey, 1986; Erb, 1987; Fourichon et al., 1999; Berry et al., 2007), and calving ease, stillbirth, and retained placenta have been report- ed to occur as a complex. This lack of independence and confounding (Thompson et al., 1983; Rajala and Gröhn, 1998) raises the possibility that the observed detrimental effect of calving ease on milk production is to some degree indirectly resulting from the effects of retained placenta and stillbirth (Fourichon et al., 1999). Correction for stillbirth and retained placenta estimates the effect of calving ease conditional on the absence of these events. This may be of value for subsequent studies, but differences will exist between these estimates and the true expected loss conditional on observing a given score. In the end, the loss of milk due to a difficult calving is of economic importance to the farmer, whether it was caused solely by difficulty at calving or in combination with related complications. Therefore, presentation of the full effect of calving ease is of primary importance to the dairy cattle industry. The effect of a difficult calving on the milk production of the dam presented in this study is purely phenotypic, and further research is needed to estimate the genetic contribution to this relationship.

Calves. This study is one of the first to attempt to estimate the effect of a difficult birth on subsequent milk production of the adult calf. The establishment of a significant long-term effect of a difficult birth on future production performance is therefore a new finding of interest in dairy cattle. However, that does not mean that this finding is entirely surprising. Studies in other species have shown that complications during the perinatal period are associated with numerous problems throughout life, including low vigor, reduction in growth, susceptibility to disease, mortality, reduction in development of the fetal central nervous system, abnormal temperament, and impaired learning ability (McNeil et al., 1970; Lundborg et al., 2003; Alonso-Spilsbury et al., 2005; Davis and Sandman, 2006; Lombard et al., 2007; Pan et al., 2007; Boksa and Zhang, 2008; Dwyer, 2008; Yoder et al., 2008; Silva et al., 2009).

At present, we can merely speculate about possible causes and mechanisms underlying the negative effects of a difficult birth on the subsequent milk production of the adult calf. Further research is needed to identify the mechanisms that underlie this phenomenon. Literature on the concept of "developmental programming" provides hypotheses that could help in understanding the specific relationship addressed in this study. The concept of developmental programming has only recently been embraced by animal agriculture, as being influential for animal growth, development, and well-being, through either in utero mechanisms or epigenetic processes (Hill et al., 2010). Therefore, studies linking prenatal and early postnatal experiences, primarily malnutrition and maternal stress, to animal performance in livestock are 
recent (Weaver et al., 2004; Ford et al., 2007; Blair et al., 2010; Du et al., 2010). Long-term changes of gene expression in the hypothalamus-pituitary-adrenal axis and mammary gland of several animal species, both by long-term chronic events and short-term acute events, have recently been reported in reviews by Kapoor et al. (2006) and Rijnkels et al. (2010). Thereby, these reviews give conceptual support to the findings in this study. Hypotheses such as developmental programming, however, need to be considered in the light of future research considering genetic correlations of calving ease with type and production.

At this time, hypothesizing is not a priority; it most important now to acknowledge that a difficult birth can have long-term effects on the performance of the adult calf and recognize that this problem needs to be addressed. The results of this study are confirmed by results of Heinrichs and Heinrichs (2011), where the effect of a difficult birth on subsequent milk production was estimated in an experimental setting (795 calves). In that study, it was found that as difficulty at delivery increased by 1 unit, first-lactation 305-d actual milk production was decreased by $284.6 \mathrm{~kg}$. This supports the equivalent estimate in this study, in which the reduction in milk production between easy and veterinary-assisted births equaled $703 \pm 251 \mathrm{~kg}$.

High expectations of the industry rest on the performance of a dairy cow, especially concerning milk production. Therefore, all events that could prohibit the animal from showing her full genetic potential should be considered, even if these events are not identifiable in surroundings of the cow in her productive life. A difficult calving evidentially has both short- and longterm effects for dam and calf, thereby strengthening the importance of calving ease as a selection trait.

\section{CONCLUSIONS}

Difficulty during first calving has detrimental effects on the performance of both the dam and adult calf. Reproductive performance of the dam in first lactation worsened following a difficult calving, with increased days to first service, number of services needed to conceive, and a prolonged calving interval. A significant loss in milk production of a veterinary-assisted dam, compared with a nonassisted dam, was shown in the first part of lactation. In the case of moderate difficulty at calving, the presence of a farmer seemed to have a beneficial effect on the milk production of both the dam and calf. Redefinition of the calving ease categories to allow inclusion of a category defined as "not observed" should therefore be considered. The establishment of a long-term effect of a difficult birth on the milk production of the calf in later life is a new finding of interest.
The general assumption that difficulties during birth do not affect subsequent calf performance because of the time interval between birth and lactation is therefore incorrect. The physiological effects or causes underlying a difficult birth appear to be long-lived. This problem needs to be addressed and further studies must be undertaken.

\section{ACKNOWLEDGMENTS}

The authors gratefully acknowledge funding from Defra (London, UK) under the Sustainable Livestock Production LINK Programme, the Scottish Government (Edinburgh, UK), CIS (Watford, UK), Cogent (Chester, UK), DairyCo (Warwickshire, UK), Genus (Cheshire, UK), Holstein UK (Rickmansworth, UK), and NMR (Chippenham, UK). Also gratefully acknowledged are the two anonymous reviewers who have contributed to this paper.

\section{REFERENCES}

Alonso-Spilsbury, M., D. Mota-Rojas, D. Villanueva-García, J. Martínez-Burnes, H. Orozco, R. Ramírez-Necoechea, A. López Mayagoita, and M. E. Trujillo. 2005. Perinatal asphyxia pathophysiology in pig and human: A review. Anim. Reprod. Sci. 90:1-30.

Barkema, H. W., Y. H. Schukken, C. L. Guard, A. Brand, and G. C. van der Weyden. 1992. Fertility, production and culling following caesarean section in dairy cattle. Theriogenology 38:589-599.

Berry, D. P., J. M. Lee, A. Macdonals, and J. R. Roche. 2007. Body condition score and body weights on dystocia and stillbirths and consequent effects on postcalving performance. J. Dairy Sci. 90:4201-4211.

Blair, H. T., C. M. C. Jenkinson, S. W. Peterson, P. R. Kenyon, D. S. van der Linden, L. C. Davenport, D. D. S. Mackenzie, S. T. Morris, and E. C. Firth. 2010. Dam/grand-dam feeding during pregnancy in sheep affects milk supply in offspring and reproductive performance in grand-offspring. J. Anim. Sci. 88:E40-E50.

Boksa, P., and Y. Zhang. 2008. Global birth hypoxia increases the neonatal testosterone surge in the rat. Neuroendocrinology 88:266275 .

Brotherstone, S. 1994. Genetic and phenotypic correlations between linear type traits in Holstein Friesian dairy cattle. Anim. Prod. 59:183-187.

Coffey, M. P., G. Simm, and S. Brotherstone. 2002. Energy balance for the first three lactations of dairy cows estimated using energy balance. J. Dairy Sci. 85:2669-2678.

Davis, E. P., and C. A. Sandman. 2006. Prenatal exposure to stress and stress hormones influences child development. Infants Young Child. 19:246-259

Dematawewa, C. M. B., and P. J. Berger. 1997. Effect of dystocia on yield, fertility, and cow losses and an economic evaluation of dystocia scores for Holsteins. J. Dairy Sci. 80:754-761.

Djemali, M., A. E. Freeman, and P. J. Berger. 1987. Reporting of dystocia scores and effects of dystocia on production, days open, and days dry from dairy herd improvement data. J. Dairy Sci. 70:2127-2131.

Dobson, H., J. E. Tebble, R. F. Smith, and W. R. Ward. 2001. Is stress really all that important? Theriogenology 55:65-73.

Drennan, M. J., and D. P. Berry. 2006. Factors affecting body condition score, live weight and reproductive performance in spring calving suckler cows. Irish J. Agric. Food Res. 45:25-38.

Du, M., J. Tong, J. Zhao, K. R. Underwood, M. Zhu, S. P. Ford, and P. W. Nathanielsz. 2010. Fetal programming of skeletal muscle development in ruminant animals. J. Anim. Sci. 88(E-Suppl.):E51E60. 
Dwyer, C. 2008. The welfare of the neonatal lamb. Small Rumin. Res. 76:31-41.

Erb, H. N. 1987. Interrelationships among production and clinical disease in dairy cattle: A review. Can. Vet. J. 28:326-329.

Erb, H. N., R. D. Smith, P. A. Oltenacu, C. L. Guard, R. B. Hillman, P. A. Powers, M. C. Smith, and M. E. White. 1985. Path model of reproductive disorders and performance, milk fever, mastitis, milk yield and culling in Holstein cows. J. Dairy Sci. 68:3337-3349.

Ford, S. P., B. W. Hess, M. M. Schwope, M. J. Nijland, J. S. Gilbert, K. A. Vonnahme, W. J. Means, H. Han, and P. W. Nathanielsz. 2007. Maternal undernutrition during early to mid-gestation in the ewe results in altered growth, adiposity, and glucose tolerance in male offspring. J. Anim. Sci. 85:1285-1294.

Fourichon, C., H. Seegers, N. Bareille, and F. Beaudeau. 1999. Effects of disease on milk production in the dairy cow: A review. Prev. Vet. Med. 41:1-35.

Garnsworthy, P. C., K. D. Sinclair, and R. Webb. 2008. Integration of physiological mechanisms that influence fertility in dairy cows. Animal 2:1144-1152.

Gilmour, A. R., B. R. Gullis, S. J. Welham, and R. Thompson. 2006 ASReml User Guide Release 2.0. VSN International Ltd., Hemel Hempstead, UK.

Heinrichs, A. J., and B. S. Heinrichs. 2011. A prospective study of calf factors affecting first-lactation and lifetime milk production and age of cows when removed from the herd. J. Dairy Sci. 94:336341.

Hill, R. A., E. E. Connor, S. P. Poulos, T. H. Welsh, and N. K. Gabler. 2010. Growth and Development Symposium: Fetal programming in animal agriculture. J. Anim. Sci. 88(E-Suppl.):E38-E39.

Hoffmann, B., I. L. Mason, and J. Schmidt. 1979. Calving Problems and Early Viability of the Calf. Current Topics in Veterinary Medicine and Animal Science, Vol. 4. Martinus Nijhoff, The Hague, the Netherlands.

Ingvartsen, K. L., R. J. Dewhurst, and N. C. Friggens. 2003. On the relationship between lactational performance and health: Is it yield or metabolistic imbalance that causes production diseases in dairy cattle? A position paper. Livest. Prod. Sci. 83:277-308.

Kapoor, A., E. Dunn, A. Kostaki, M. H. Andrews, and S. G. Matthews. 2006. Fetal programming of hypothalamo-pituitary-adrenal function: Prenatal stress and glucocorticoids. J. Physiol. 572:31-44.

Laster, D. B., H. A. Glimp, L. V. Cundiff, and K. E. Gregory. 1973. Factors affecting dystocia and the effects of dystocia on subsequent reproduction in beef cattle. J. Anim. Sci. 36:695-705.

Laster, D. B., and K. E. Gregory. 1973. Factors influencing peri- and early postnatal calf mortality. J. Anim. Sci. 37:1092-1097.

Lombard, J. E., F. B. Garry, S. M. Tomlinson, and L. P. Garber. 2007. Impacts of dystocia on health and survival of dairy calves. J. Dairy Sci. 90:1751-1760.

Lundborg, G. K., P. A. Oltenacu, D. O. Maizon, E. C. Svensson, and P. G. A. Liberg. 2003. Dam related effects on heart girth at birth, morbidity and growth rate from birth to 90 days of age in Swedish dairy calves. Prev. Vet. Med. 60:175-190.

Mangurkar, B. R., J. F. Hayes, and J. E. Moxley. 1984. Effects of calving ease-calf survival on production and reproduction in Holsteins. J. Dairy Sci. 67:1496-1509.

McNeil, T. F., R. Wiegerink, and J. E. Dozier. 1970. Pregnancy and birth complications in the births of seriously, moderately, and mildly behaviorally disturbed children. J. Nerv. Ment. Dis. 151:24-34.

Mee, J. F. 2008. Prevalence and risk factors for dystocia in dairy cattle: A review. Vet. J. 176:93-101.

Meijering, A. 1983. Dystocia and stillbirth in cattle - A review of causes relations and implications. Livest. Prod. Sci. 11:143-177.
Pan, H. Q., J. M. Kerns, D. L. Lin, S. Liu, N. Esparza, and M. S. Damaser. 2007. Increased duration of simulated childbirth injuries results in increased time to recovery. Am. J. Physiol. Regul. Integr. Comp. Physiol. 292:R1738-R1744.

Peter, A. T., P. L. A. M. Vos, and D. J. Ambrose. 2009. Postpartum anestrus in dairy cattle. Theriogenology 71:1333-1342.

Pryce, J. E., M. D. Royal, P. C. Garnsworthy, and I. L. Mao. 2004. Fertility in the high-producing dairy cow. Livest. Prod. Sci. 86:125-135.

Rajala, P. J., and Y. T. Gröhn. 1998. Effects of dystocia, retained placenta, and metritis on milk yield in dairy cows. J. Dairy Sci. 81:3172-3181.

Rijnkels, M., E. Kabotyanski, M. B. Montazer-Torbati, C. Hue Beauvais, Y. Vassetzky, J. M. Rosen, and E. Devinoy. 2010. The epigenetic landscape of mammary gland development and functional differentiation. J. Mammary Gland Biol. Neoplasia 15:85-100.

Rowlands, G. J., and S. Lucey. 1986. Changes in milk yield in dairy cows associated with metabolic and reproductive disease and lameness. Prev. Vet. Med. 4:205-221.

SAS Institute. 2006. SAS/STAT Software. Release 9.1, SAS Institute Inc., Cary, NC.

Senger, P. L. 2003. Pathways to Pregnancy and Parturition. 2nd rev. ed. Current Conceptions Inc., Pullman, WA.

Silva, L. C. G., C. F. Lucio, G. A. L. Veiga, J. A. Rodrigues, and C. I. Vannucchi. 2009. Neonatal clinical evaluation, blood gas and radiographic assessment after normal birth, vaginal dystocia or caesarean section in dogs. Reprod. Domest. Anim. 44:160-163.

Simerl, N. A., C. J. Wilcox, and W. W. Thatcher. 1992. Postpartum performance of dairy heifers freshening at young ages. J. Dairy Sci. 75:590-595.

Tenhagen, B. A., D. Edinger, and W. Heuwieser. 1999. Impact of dystocia in primiparous cows on lactational performance and survival. Tierarztl. Umsch. 54:617-623.

Tenhagen, B. A., A. Helmbold, and W. Heuwieser. 2007. Effect of various degrees of dystocia in dairy cattle on calf viability, milk production, fertility and culling. J. Vet. Med. A Physiol. Pathol. Clin. Med. 54:98-102.

Thompson, J. R., E. J. Pollak, and C. L. Pelissier. 1983. Interrelationships of parturition problems, production subsequent lactation, reproduction and age at first calving. J. Dairy Sci. 66:1119-1127.

Wall, E., M. P. Coffey, and S. Brotherstone. 2005. Body trait profiles in Holstein-Friesians modeled using random regression. J. Dairy Sci. 88:3663-3671.

Weaver, I. C. G., N. Cervoni, F. A. Champagne, A. C. D'Alessio, S. Sharma, J. R. Seckl, S. Dymov, M. Szyf, and M. J. Meaney. 2004. Epigenetic programming by maternal behaviour. Nat. Neurosci. $7: 847-854$.

White, I. M. S., R. Thompson, and S. Brotherstone. 1999. Genetic and environmental smoothing of lactation curves with cubic splines. J. Dairy Sci. 82:632-638.

Wilmink, J. B. M. 1987. Adjustment of lactation yield for age at calving in relation to level of production. Livest. Prod. Sci. 16:321334

Yoder, B. A., M. C. Gordon, and W. H. Barth Jr. 2008. Late-preterm birth: Does the changing obstetric paradigm alter the epidemiology of respiratory complications? Obstet. Gynecol. 111:814-822.

Zhang, W. C., T. Nakao, M. Moriyoshim, K. Nakada, A. Y. Ribadu, T. Ohtaki, and Y. Tanaka. 1999. Relationship of maternal plasma progesterone and estrone sulphate to dyctocia in Holstein-Friesian heifers and cows. J. Vet. Med. Sci. 61:909-913. 